\title{
Reference values for touch sensibility thresholds in healthy Nepalese volunteers
}

\author{
C. M. KETS*, M. E. VAN LEERDAM*, \\ W. H. VAN BRAKEL*§, W. DEVILLÉ $\dagger$ \\ \& F. W. BERTELSMANN $\ddagger$ \\ *Green Pastures Hospital, Pokhara, Nepal; †Department of Epi- \\ demiology and Biostatistics, Free University, Van der Boechors- \\ straat 7, 1081 BT Amsterdam, The Netherlands; $\ddagger$ Department of \\ Neurology, Free University Hospital, De Boelelaan 1117, $1081 \mathrm{HV}$, \\ Amsterdam, The Netherlands
}

\section{Accepted for publication 19 September 1995}

Summary A hundred and thirty-six apparently healthy volunteers between the ages of 16 and 67 were used to determine normative thresholds of tactile sensibility in the Nepali adult population.

Tactile sensibility thresholds on standardized sites on hands and feet were assessed for two sensory tests: Semmes-Weinstein monofilaments (SWM) and moving-point discrimination (M2PD). Results are reported as the proportion of subjects able to feel a given threshold. The effect of age, sex, side, occupation, smoking habit and alcohol consumption on the results was examined with quantile regression.

On the hand $200 \mathrm{mg}$ seemed an appropriate threshold for 'normal' touch sensibility measured with monofilaments. About $99 \%$ (95\% confidence interval 97-100) of individuals could detect this filament at all sites. A similar proportion could discriminate two points $4 \mathrm{~mm}$ apart which were moved from proximal to distal on the volar pad of the distal phalanx of the index and little finger. For the sole of the foot the thresholds were $2 \mathrm{~g}$ and $8 \mathrm{~mm}$. Variability of results was greatest at the heel.

Normal thresholds for tactile sensibility were higher than those published for the North American population. Monofilament thresholds suitable for screening were $200 \mathrm{mg}(\log$ number 3.61$)$ and $2 \mathrm{~g}(\log$ number 4.31$)$ for hand and foot, respectively. For moving 2-point discrimination on the hand this threshold was $4 \mathrm{~mm}$.

\section{Introduction}

Mycobacterium leprae specifically affect the peripheral nerves causing functional $\S$ Correspondence: W. H. van Brakel, c/o INF LP, P.O. Box 5, Pokhara, Nepal 
impairment. The resulting anaesthesia of the skin and muscle weakness are the major causes of disability and mutilations. In an early stage of leprosy the neural damage can usually be reversed by treatment. ${ }^{1-3}$ Therefore early detection and prevention of neural damage are very important. A detailed assessment of any neural deficit and periodic retesting are useful objective guides of management during treatment. ${ }^{1-5}$ In Nepal, Semmes-Weinstein monofilaments (SWM), and, to a lesser degree, moving two-point discrimination (M2PD) are used to detect impairment of sensibility in the hands and feet of leprosy patients. Published normative data are based on the thresholds of sensibility in healthy subjects in the United States. ${ }^{4,6-8}$ It seemed likely that these normal values would not be appropriate for evaluating tests on rural Nepali patients, many of whom are farmers or manual labourers usually only wearing loosely fitting plastic chappals as footwear. Therefore, we wished to determine the thresholds of sensibility for SWM and M2PD in hands and feet of healthy Nepali people. We investigated the influence of age, sex, smoking, alcohol consumption, occupation, and right and left sides in hand and foot.

\section{Material and methods}

SUBJECTS

Seventy-four male and 62 female healthy Nepali volunteers (272 hands and feet) were tested. Each subject was asked some questions on matters that might influence the test results, including age, sex, occupation, complaints about health, medicines used, alcohol consumption, smoking and use of footwear. They were healthy, not known to have had leprosy and they did not receive any medication known to interfere with sensory function. The volunteers consisted of three different groups:

Sixty-nine students at the forestry campus in Pokhara. The students were young, aged 16-22, and were not used to physical labour.

Forty-six volunteers from the village Ghachok, most of whom were farmers engaged in manual labour.

Twenty-one volunteers around the 'Pipal trees', the social meeting places in Pokhara. These had either manual and/or non-manual jobs.

THE SEMMES-WEINSTEIN MONOFILAMENTS (SWM)

A set of 10 monofilaments of equal length with diameters ranging from $0 \cdot 13$ to $1 \cdot 14 \mathrm{~mm}$ was used to assess light touch sensibility. The force necessary to bend the filament depends on the filament's diameter and is precalibrated $(70 \mathrm{mg}-280 \mathrm{~g})$. The marking numbers are derived from a log scale, corresponding to the log of the force exerted by that filament in $0 \cdot 1 \mathrm{mg}$ units (see Table 1). The 70 to $750 \mathrm{mg}$ filaments are applied to the same site three times because these thinner filaments slip more easily and one touch might not reach the threshold force of the filament. The 1 to $280 \mathrm{~g}$ filaments only need to be applied once. The filament is applied perpendicular to the tested area in such a way that it bends slightly. ${ }^{11}$ The subject, who has his eyes closed, is asked to respond with 'yes' each time the filament is felt. A quiet environment is recommended for testing with both monofilaments and moving two-point discrimination, because the subjects' 
Table 1. Semmes-Weinstein Monofilaments used in the study, with log scales, corresponding forces and rounded measured forces

\begin{tabular}{|c|c|c|c|c|c|c|}
\hline $\begin{array}{l}\text { Marking } \\
\text { number* }\end{array}$ & $\begin{array}{l}\text { Diameter } \\
(\mathrm{mm})\end{array}$ & $\begin{array}{l}\text { SW force } \dagger \\
\text { (g) }\end{array}$ & $\begin{array}{l}\text { LPR force } \\
\text { (g) }\end{array}$ & $\begin{array}{l}\text { BT force } \S \\
\text { (g) }\end{array}$ & $\begin{array}{l}\text { Stress } \\
\left(\mathrm{g} / \mathrm{mm}^{2}\right)\end{array}$ & $\begin{array}{c}\text { Force** } \\
\text { (milli-Newtons) }\end{array}$ \\
\hline $2 \cdot 83$ & $0 \cdot 132$ & 0.068 & 0.091 & 0.072 & $6 \cdot 52$ & 0.71 \\
\hline $3 \cdot 22$ & $0 \cdot 137$ & $0 \cdot 166$ & $0 \cdot 112$ & $0 \cdot 172$ & $7 \cdot 50$ & 1.69 \\
\hline $3 \cdot 61$ & $0 \cdot 171$ & $0 \cdot 408$ & $0 \cdot 213$ & $0 \cdot 205$ & $9 \cdot 29$ & $2 \cdot 01$ \\
\hline $3 \cdot 84$ & $0 \cdot 214$ & 0.697 & 0.562 & 0.445 & $15 \cdot 7$ & $4 \cdot 36$ \\
\hline $4 \cdot 08$ & $0 \cdot 228$ & $1 \cdot 194$ & 0.977 & 0.745 & $23 \cdot 9$ & $7 \cdot 30$ \\
\hline $4 \cdot 17$ & $0 \cdot 244$ & 1.494 & $1 \cdot 58$ & 0.977 & $33 \cdot 7$ & $9 \cdot 57$ \\
\hline $4 \cdot 31$ & $0 \cdot 284$ & $2 \cdot 062$ & 1.85 & $2 \cdot 35 \dagger+$ & $29 \cdot 5$ & $23 \cdot 0$ \\
\hline $4 \cdot 56$ & $0 \cdot 313$ & $3 \cdot 632$ & $2 \cdot 81$ & $4.91 \dagger \dagger$ & $36 \cdot 6$ & $48 \cdot 1$ \\
\hline $5 \cdot 07$ & 0.475 & $11 \cdot 7$ & $17 \cdot 0$ & $7 \cdot 37$ & 94.9 & $72 \cdot 2$ \\
\hline $6 \cdot 65$ & $1 \cdot 142$ & 447 & - & 279 & - & 2734 \\
\hline
\end{tabular}

Adapted from Levin, Pearsall \& Ruderman ${ }^{11}$ and Bell \& Tomancik. ${ }^{9}$

* corresponds to $\log _{10}$ of force in $0 \cdot 1 \mathrm{mg}$ units, $\dagger$ force published by Weinstein, $\ddagger$ actual force measured by Levin et al. (at least 10 applications/filament on a top-loading balance), $\S$ actual force measured by Bell \& Tomancik (105 applications/filament on strain gauge device), 9 actual stress measured by Levin et al. ${ }^{*}$ force in $\mathrm{mN}$ calculated from column 5 by multiplying the force in grams by $9 \cdot 8$ (conversion factor at sea level), $\dagger \dagger$ actual force measured by Bell \& Tomancik (280 applications/filament; 28 different kits).

concentration is important. ${ }^{7}$ The following areas were tested on the palmar surface of the hand and the sole of the foot:

Median nerve: on the distal phalanx of the index finger, the skin over the 2nd metacarpophalangeal joint (MCP2) and on the distal phalanx of the thumb.

Ulnar nerve: on the distal phalanx of the little finger, the skin over the 5th metacarpophalangeal joint and proximally on the hypothenar eminence.

Posterior tibial nerve: on the distal phalanx of the big toe, the skin over the 1st and 5th metatarsophalangeal (MTP) joints and on the centre of the heel.

MOVING TWO-POINT DISCRIMINATION (M2PD)

A Disk-Criminator ${ }^{\circledR}$ was used for moving two-point discrimination. This is a disk with metal prongs different distances apart, developed by Mackinnon and Dellon. ${ }^{12}$ The least possible pressure is given while moving the prongs along the surface of the finger from proximal to distal, parallel to the long axis of the finger. Testing began with two prongs $6 \mathrm{~mm}$ apart and was continued with diminishing (or increasing) distances until the subject was just able to distinguish between one or two prongs. One or two prongs were used randomly. The minimum distance in millimetres was taken as the smallest distance for which two correct answers out of three attempts were given. ${ }^{12}$

Test sites used were: the distal phalanx of the index, little fingers on the hand; and the big toe and heel on the foot.

The SWM tests were performed by the physiotechnicians from Green Pastures Hospital. M2PD was tested by both the physiotechnicians and the investigators, CMK, MvL and IBK. The hand or foot to be tested was caref ully positioned and supported by a cushion or towel to prevent movement or tiredness. 
STATISTICAL ANALYSIS

As the distribution of the test values in the healthy volunteers was not normally distributed (the majority of subjects could feel the thinner filaments or smaller distances) we decided to report the proportion of subjects that could detect a given threshold. The reported threshold filaments and interprong distances were chosen such that they were closest to the $97 \cdot 5$ th and 99 th percentiles for the respective test site. The percentages are given with their $95 \%$ confidence interval. The latter represent the range of values within which the true value lies, with a probability of $95 \%$. All analyses were done separately for 'right' and 'left' because the thresholds on both hands or feet of the same subject are neither necessarily identical, nor statistically independent.

The influence of sex, smoking, alcohol and occupation upon the results was tested by using univariate analysis by the non-parametric Wilcoxon Rank Sum test. ${ }^{13}$ Quantile regression, ${ }^{14}$ a nonparametric regression technique, was employed to assess the association between the different factors and the results. The Wilcoxon matched-pairs signed-ranks test was used to determine whether or not there was a significant difference between results of testing right and left hands. ${ }^{13} \mathrm{~A} p$-value of less than $5 \%$ was taken as the level of statistical significance.

\section{Results}

The subjects' ages ranged from 16 to 67 and the distribution is shown in Figure 1. Table 2 shows the distribution of the co-factors investigated in this group of subjects. Fifty-six percent were non-manual workers and $44 \%$ were manual workers. Twenty-five percent were smokers and $16 \%$ drank alcohol. Ninety-one percent of subjects used no medicines, the variety of different medicines taken by the other $9 \%$ did not include any that are known to interfere with sensory functions. Eighty-six percent had no physical complaints and the rest of the complaints were not of a neurological nature.

The 70 -mg filament was felt by $95 \cdot 2-96 \cdot 7 \%$ of the subjects on the thumb, MCP2, the

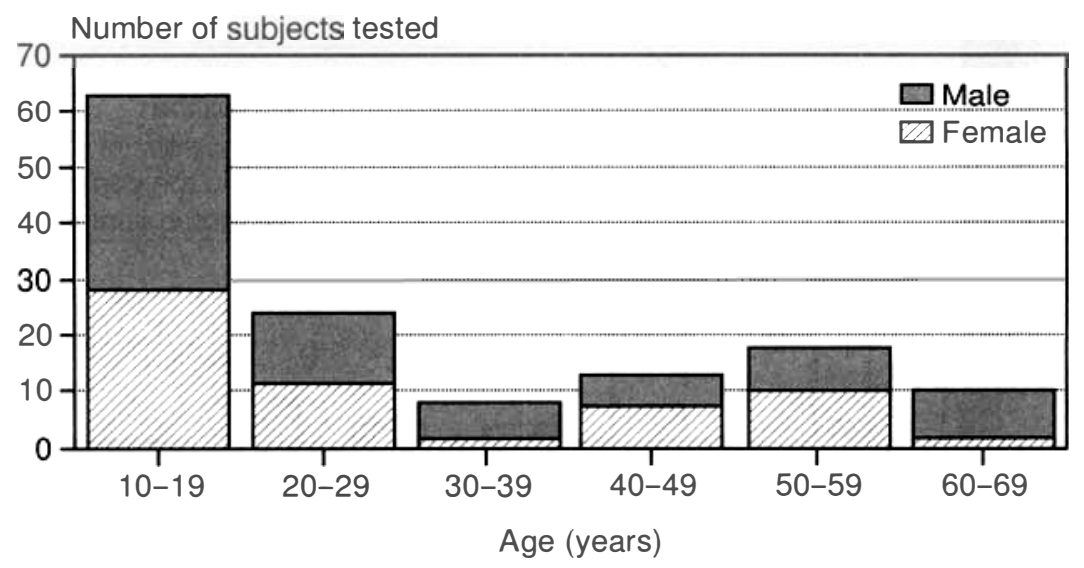

Figure 1. Age and sex distribution among study subjects. 
Table 2. Distribution of co-factors among the study subjects $(N=136)$

\begin{tabular}{|c|c|c|c|c|c|c|}
\hline \multirow[b]{2}{*}{ Co-factor } & \multicolumn{3}{|c|}{ Male $(N=75)$} & \multicolumn{3}{|c|}{ Female $(N=61)$} \\
\hline & Yes $(\%)$ & No $(\%)$ & Unclear $(\%)$ & Yes $(\%)$ & No $(\%)$ & Unclear $(\%)$ \\
\hline Manual labour & $29(38 \cdot 7)$ & $46(61 \cdot 3)$ & & $34(55 \cdot 7)$ & $27(44 \cdot 3)$ & \\
\hline Using footwear & $63(84)$ & $1(1 \cdot 3)$ & $11(14 \cdot 7)$ & $60(98.4)$ & $1(1 \cdot 6)$ & \\
\hline Smoking & $19(25 \cdot 3)$ & $56(74 \cdot 7)$ & & $14(23)$ & $44(72 \cdot 1)$ & $3(4 \cdot 9)$ \\
\hline Uses alcohol & $17(22 \cdot 7)$ & $58(77 \cdot 3)$ & & $4(6 \cdot 6)$ & $54(88 \cdot 5)$ & $3(4.9)$ \\
\hline
\end{tabular}

index finger and the hypothenar eminence. This filament was felt by $93 \cdot 0$ and $94 \cdot 1 \%$, respectively, on the little finger and MCP5. Figure 2 illustrates the distribution of filament thresholds found for the thumb and the big toe in our sample. Because the 70-mg filament was the thinnest filament used, the data were non-normally distributed, particularly on the hand.

Table 3 shows the proportions of subjects feeling the filament nearest to the $97 \cdot 5$ and 99th percentiles. There were no significant differences between right and left sides. The 200 -mg filament was felt on the big toe by only $58.7 \%$, on MTP1 by $70 \cdot 9 \%$, on MTP5 by $68.8 \%$ and on the heel by $31 \cdot 3 \%$ of the subjects. The big toe, MTP1 and MTP5 had a reference SWM threshold of $2 \mathrm{~g}$, using the $97 \cdot 5$ percentile as cut off level. Four grammes appeared a more relevant normal value for the heel.

A M2PD threshold of $2 \mathrm{~mm}$ was felt by $84.3 \%$ of the subjects on the index finger and by $73.8 \%$ on the little finger. Table 4 shows the results near the 97.5 and 99 th percentiles of testing with M2PD. Using the 97.5 percentile as cut off level, M2PD had a reference threshold of $4 \mathrm{~mm}$ for the index and the little fingers.

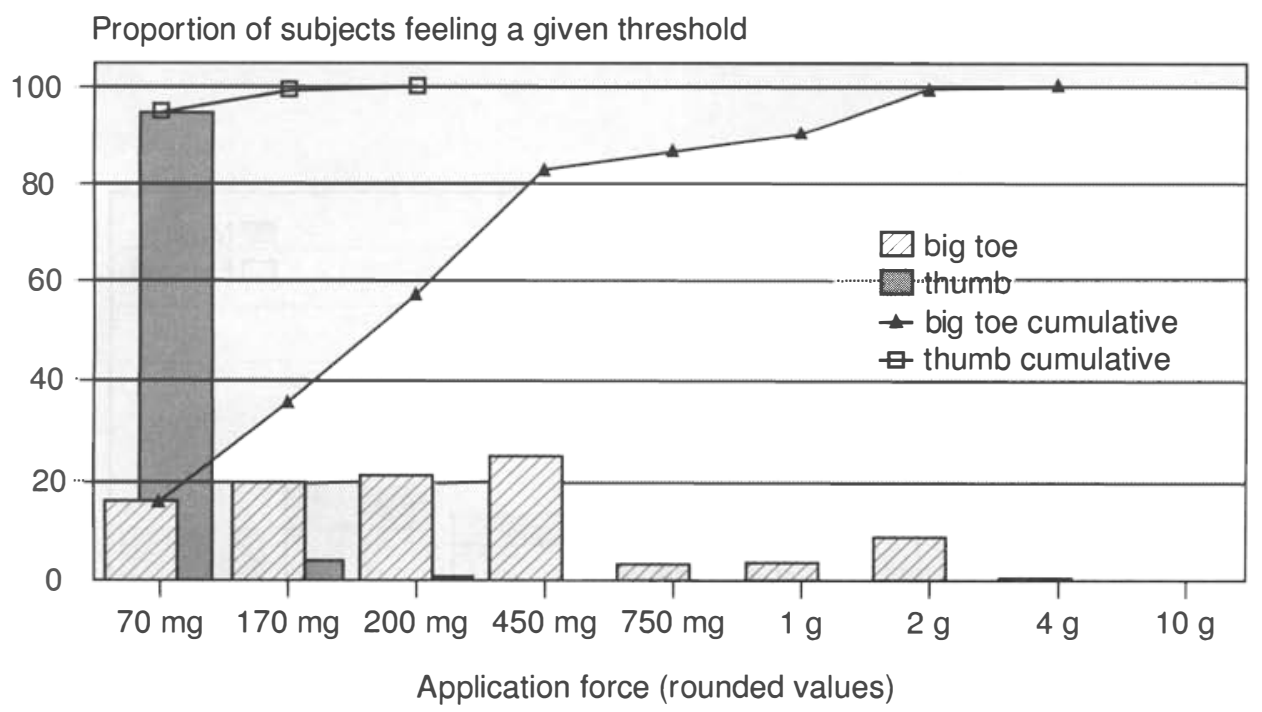

Figure 2. Distribution of monofilament scores on the thumb and big toe $(N=136)$. 
Table 3. Touch sensibility thresholds in healthy Nepali volunteers measured with Semmes-Weinstein Monofilaments (136 pairs of hands and 134 pairs of feet) and the proportion of people feeling that particular threshold (with the $95 \%$ confidence interval)

\begin{tabular}{|c|c|c|c|c|c|c|}
\hline Site & Threshold & Left & Right & Threshold & Left & Right \\
\hline \multicolumn{7}{|c|}{ Median nerve } \\
\hline Thumb & $170 \mathrm{mg}$ & $97 \cdot 1(94 \cdot 2-100)$ & $99 \cdot 3(97 \cdot 9-100)$ & $200 \mathrm{mg}$ & $99 \cdot 3(97 \cdot 9-100)$ & 100 \\
\hline MCP2 & $170 \mathrm{mg}$ & $97 \cdot 1(94 \cdot 2-100)$ & $98 \cdot 5(96 \cdot 5-100)$ & $200 \mathrm{mg}$ & $99 \cdot 3(97 \cdot 9-100)$ & 100 \\
\hline Index & $170 \mathrm{mg}$ & $97 \cdot 1(94 \cdot 2-100)$ & $98 \cdot 5(96 \cdot 5-100)$ & $200 \mathrm{mg}$ & $99 \cdot 3(97 \cdot 9-100)$ & 100 \\
\hline \multicolumn{7}{|c|}{ Ulnar nerve } \\
\hline Little & $170 \mathrm{mg}$ & $97 \cdot 8(95 \cdot 3-100)$ & $97 \cdot 1(94 \cdot 2-100)$ & $200 \mathrm{mg}$ & $99 \cdot 3(97 \cdot 9-100)$ & $99 \cdot 3(97 \cdot 9-100)$ \\
\hline MCP5 & $170 \mathrm{mg}$ & $97 \cdot 1(94 \cdot 2-100)$ & $97 \cdot 8(95 \cdot 3-100)$ & $200 \mathrm{mg}$ & $98 \cdot 5(96 \cdot 5-100)$ & $99 \cdot 3(97 \cdot 9-100)$ \\
\hline Hyp & $170 \mathrm{mg}$ & $97 \cdot 1(94 \cdot 2-100)$ & $98 \cdot 5(96 \cdot 5-100)$ & $200 \mathrm{mg}$ & 100 & $99 \cdot 3(97 \cdot 9-100)$ \\
\hline \multicolumn{7}{|c|}{ Post tibial nerve } \\
\hline Big toe & $2 \mathrm{~g}$ & $99 \cdot 3(97 \cdot 9-100)$ & $99 \cdot 3(97 \cdot 9-100)$ & $4 \mathrm{~g}$ & $99 \cdot 3(97 \cdot 9-100)$ & 100 \\
\hline MTP1 & $2 \mathrm{~g}$ & 100 & $98 \cdot 5(96 \cdot 5-100)$ & $4 \mathrm{~g}$ & 100 & 100 \\
\hline MTP5 & $2 \mathrm{~g}$ & $99 \cdot 3(97 \cdot 9-100)$ & $99 \cdot 3(97 \cdot 9-100)$ & $4 \mathrm{~g}$ & $99 \cdot 3(97 \cdot 9-100)$ & 100 \\
\hline Heel & $2 \mathrm{~g}$ & $95 \cdot 5(92 \cdot 0-99 \cdot 0)$ & $94 \cdot 8(91 \cdot 1-98 \cdot 5)$ & $4 \mathrm{gm}$ & $98 \cdot 5(96 \cdot 3-100)$ & $97 \cdot 0(94 \cdot 1-99 \cdot 9)$ \\
\hline
\end{tabular}

$\mathrm{mg}=$ milligrammes, $\mathrm{g}=$ grammes. 
Table 4. Moving 2-point discrimination thresholds in healthy Nepali volunteers (133 pairs of hands and 112 pairs of feet) and the proportion of people feeling that particular threshold (with the $95 \%$ confidence interval).

\begin{tabular}{|c|c|c|c|c|c|c|}
\hline Site & Threshold & Left & Right & Threshold & Left & Right \\
\hline $\begin{array}{l}\text { Median nerve } \\
\text { Index }\end{array}$ & $3 \mathrm{~mm}$ & $97 \cdot 0(94 \cdot 1-99 \cdot 9)$ & $97 \cdot 0(92 \cdot 9-100)$ & $4 \mathrm{~mm}$ & 100 & 100 \\
\hline $\begin{array}{l}\text { Ulnar nerve } \\
\text { Little }\end{array}$ & $3 \mathrm{~mm}$ & $91 \cdot 2(86 \cdot 1-96 \cdot 3)$ & $91 \cdot 8(87 \cdot 1-96 \cdot 5)$ & $4 \mathrm{~mm}$ & $99 \cdot 2(97 \cdot 6-100)$ & $98 \cdot 5(96 \cdot 3-100)$ \\
\hline $\begin{array}{l}\text { Post tibial nerve } \\
\text { Big toe } \\
\text { Heel }\end{array}$ & $\begin{array}{l}6 \mathrm{~mm} \\
7 \mathrm{~mm}\end{array}$ & $\begin{array}{l}97 \cdot 3(94 \cdot 4-100) \\
96 \cdot 4(92 \cdot 9-99 \cdot 9)\end{array}$ & $\begin{array}{l}97 \cdot 3(94 \cdot 4-100) \\
93 \cdot 7(89 \cdot 2-98 \cdot 2)\end{array}$ & $\begin{array}{l}7 \mathrm{~mm} \\
8 \mathrm{~mm}\end{array}$ & $\begin{array}{l}98 \cdot 2(95 \cdot 7-100) \\
98 \cdot 2(95 \cdot 7-100)\end{array}$ & $\begin{array}{l}99 \cdot 1(97 \cdot 3-100) \\
99 \cdot 1(97 \cdot 3-100)\end{array}$ \\
\hline
\end{tabular}

$\mathrm{mm}=$ millimetres. 
For both the SWM and M2PD there was a significant difference between the thresholds on the heel and the rest of the foot $(p=0 \cdot 001)$.

\section{SIGNIFICANT VARIABLES}

In univariate analysis, the touch thresholds of hands and feet were associated with smoking and type of work, smokers and manual workers having a higher threshold than nonsmokers and non-manual workers ( $p<0.01$ and $p<0.001$, respectively). Sensibility thresholds increased with age. When using a multivariate regression model (quantile regression, and the 95th quantile) age was the only variable found to have a significant effect on touch thresholds on several sites on hands and feet after adjusting for the effects of sex, type of work, smoking and use of alcohol.

\section{Discussion}

Indentation of the skin is currently believed to be the most quantifiable way of measuring touch perception. ${ }^{15}$ Either the application force or the skin displacement is measured. Ideally the stimuli should be controlled with a known waveform that is invariant over a broad range of stimulus magnitudes. ${ }^{15}$ This is only possible with automated instruments that deliver controlled stimuli using electromechanical transducers. It is clear, however, that in most clinics such equipment will not be available in the foreseeable future. This is particularly true in the field of leprosy where most patients are treated in rural clinics with minimal resources. The Semmes-Weinstein Monofilaments and moving 2-point discrimination provide practical and economical alternatives which give quantifiable results.

The study was carried out under difficult but not uncommon conditions in leprosy field work. The environment for testing was not ideal; spectators may have distracted the subjects and testers. This may have increased variability in results. Our findings are therefore likely to be useful under operational conditions.

Abnormal sensibility may be caused by a variety of diseases, the most common of which are leprosy, diabetes, Dupuytren's contracture and carpal tunnel syndrome. When unusually high thresholds were found, particular care was exercised to exclude these diseases. However, prevailing circumstances made it difficult to apply additional tests routinely.

\section{SEMMES-WEINSTEIN MONOFILAMENTS}

The monofilaments or 'von Frey hairs', as they are often referred to , can deliver a touchpressure stimulus that is constant for any given filament, provided the application force is enough to bend the filament. ${ }^{16,17}$ Care should be taken to apply the filament perpendicularly to the skin, so that the tip does not slip and that the resulting deformation of the filament is crescent-shaped and not 'S-shaped'.1 Too fast an application may result in 'ringing', an initial spike of force, which may exceed the buckling force of the filament. ${ }^{17}$ The material used for the standardized filaments is straight monofilament nylon, the kind that is used to manufacture toothbrushes. The 
diameters are standardized (see Table 1) and the length of filaments should be $38 \mathrm{~mm} .^{7}$ Where possible, diameter and length should be checked before use since the filament's force is influenced by these factors. ${ }^{9}$ Monofilaments should be checked before each testing session, because an already bent filament will give less force. Bent filaments that cannot be straightened easily should be replaced.

Using the $97 \cdot 5$ percentile as cut off for 'normal', we found that both the $200-\mathrm{mg}$ filament and 170-mg filament would be acceptable as reference thresholds. However, the 200-mg filament (log no. 3.61) was chosen as the reference point for several reasons:

It was appreciated by a larger proportion of subjects $(98 \cdot 5-100 \%)$, thus increasing the specificity of the test.

Because of its diameter, it is more robust than the 170-mg filament, and will last longer. It is therefore more suitable for use under field conditions than the more vulnerable 170and 70-mg filaments.

It is currently available in bulk as loose filaments (through the American Leprosy Missions) and can be easily fitted into locally made handles.

If a patient feels the 200 -mg monofilament, there is almost a $100 \%$ chance that the patient's sensibility is intact (high specificity). This is very important because treatment may be given based on the results of monofilament testing. On the other hand, choosing a higher threshold as normal will give an increase of false negative results (low sensitivity). Patients with a decreased sensibility, but still feeling the $200-\mathrm{mg}$ monofilament, will not be recognized as having a dangerous impairment of neural function. ${ }^{15}$

On the foot, the 2-g filament (log no. 4.31) appeared to be appropriate as reference threshold (Table 3). The reference thresholds of the SWM found in the USA were 45$70 \mathrm{mg}$ for the hand and approximately $300 \mathrm{mg}$ for the foot. ${ }^{4,7,8}$

\section{MOVING 2-POINT DISCRIMINATION}

Moving 2-point discrimination (M2PD) has been advocated as a test of innervation density of the rapidly-adapting fibre system. ${ }^{6}$ While using this test, the application force must be kept as constant as possible in order to minimize the variability in the test results caused by the examiner. A study of interobserver repeatability using these tests will be published elsewhere (van Brakel et al., submitted). Testing moving twopoint discrimination on the foot was very difficult. As many subjects were guessing, it was almost impossible to get reliable thresholds. This may be due to the fact that the sole of the foot is not used for finer tactile discrimination and also because the formation of callosities on the sole is more marked than on the hand.

Appropriate reference thresholds for M2PD in our sample were $4 \mathrm{~mm}$ for the hands and $7 \mathrm{~mm}$ for the big toe. Our experience suggested that testing of M2PD on the sole of the foot, particularly on the heel, cannot be recommended. Dellon found a reference value of $2 \mathrm{~mm}$ in the distal tip of the finger, while a value of $3 \mathrm{~mm}$ was regarded as an early abnormal value. ${ }^{6,8}$

Compared to American reference values, the Nepali reference values are higher especially on the foot, both for the SWM and the M2PD. This difference may be explained by a higher proportion of people walking barefoot or in chappals (sandals). ${ }^{18}$ This applies to both manual and non-manual workers compared to those in the North American samples. Manual work and lack of footwear increase the tendency to 
formation of callosities on hands and soles of feet which might lead to higher thresholds of sensibility. ${ }^{18}$

When analysing the determinants of sensory threshold (explanatory variables), age was the only factor significantly associated with the level of threshold after adjusting for the effects of factors such as occupation and smoking in a multivariate model. The sensory threshold increased with age on most of the sites tested. Unfortunately, the sample size of our study was not big enough to produce age band-specific normative values. A similar age dependency of thresholds of touch sensibility was described by Dyck. ${ }^{19}$ A much larger sample will be needed to provide us with the age-specific normal thresholds.

\section{Conclusions}

The reference values for monofilaments used in the USA are unsuitable in Nepal. For the hand we found the 200-mg filament to be the most suitable reference value, and for the foot this was the 2-g filament (instead of $70 \mathrm{mg}$ and $300 \mathrm{mg}$, respectively).

We found a reference threshold of $4 \mathrm{~mm}$ for moving two-point discrimination of the hand (instead of $2 \mathrm{~mm}$, which is used as threshold for reference in the USA).

We do not recommend the use of moving two-point discrimination on the foot.

\section{Acknowledgments}

We wish to thank Mr Ishwar Khawas and the staff of the Physiotherapy Department at Green Pastures Hospital for their help in this study. One anonymous referee provided many valuable suggestions and corrections on an earlier draft of this article.

\section{References}

1 Bryceson A, Pfaltzgraff RE, ed. Leprosy, 3rd edition. Churchill Livingstone, Edinburgh, 1990.

2 Lechat ME. Control programs in leprosy. In: Leprosy, Hastings RC (ed) Churchill Livingstone Edinburgh etc, 1985: 253-268.

${ }^{3}$ Palande DD, Bowden REM. Early detection of damage to nerves in leprosy. Lepr Rev, 1992; 63: 60-72.

${ }^{4}$ Bell-Krotoski JA. International project to measure peripheral nerve involvement underlying disability of the hand in Hansen's disease. Gillis W. Long Hansen's disease center Carville, LA 70721, 1989.

5 Watson JM. Preventing disability in leprosy patients. The Leprosy Mission International. Stanley L. Hunt (printers) Ltd, 1988.

6 Dellon AL. The moving two-point discrimination test: Clinical evaluation of the quickly adapting fiber/ receptor system. J Hand Surg, 1978; 5: 474-480.

7 Bell-Krotoski JA. Light touch/deep pressure testing using Semmes-Weinstein monofilaments. In: Rehabilitation of the hand, 3rd ed. Hunter et al. (eds) C. V. Mosby Co. 1989; 575-593.

8 Dellon AL. Evaluation of sensibility and re-education of sensation in the hand. John D. Lucas Printing Co, 1988.

9 Bell-Krotoski JA, Tomancik E. The repeatability of testing with Semmes-Weinstein Monofilaments. $J$ Hand Surg, 1987; 12A: 155-61.

10 Brandsma JW, Strien GV, Bernards ATM, Oostendorp RAB. Onderzoek van de drukperceptie met monofilamenten. Stichting Wetenschap en Scholing Fysiotherapie Amersfoort.

11 Levin S, Pearshall G, Ruderman R. Von Frey's method of measuring pressure sensibility in the hand: an engineering analysis of the Weinstein-Semmes pressure aesthesiometer. J Hand Surg, 1978; 3: 211-6.

12 Dellon AL, Mackinnon SE, McDonald Crosby P. Reliability of two-point discrimination measurements; $J$ Hand Surg, 1987; 12A: 693-6. 
13 Kirkwood BR. Essentials of medical statistics. Blackwell Scientific Publications, Oxf ord, 1988: pp. 147-9.

${ }_{14}$ Clayton D, Hills M. Statistical models in epidemiology. Oxford University Press, Oxford, 1993: p. 229 ff.

15 Quantitative sensory testing: a consensus report from the Peripheral Neuropathy Association. Neurol 1993; 43: 1050-2.

16 Bell-Krotoski JA, Buford Jr WL. The force/time relationship of clinically used sensory testing instruments. $J$ Hand Ther, 1988; Jan-Mar: 76-85.

17 Johansson RS, Vallbo AB, Westling G. Thresholds of mechanosensitive afferents in the human hand as measured with von Frey hairs. Brain Res, 1980; 184: 353-51.

18 Stratford CJ, Owen BM. The effect of footwear on sensory testing in leprosy. Lepr Rev, 1994; 65: 58-65.

19 Dyck PJ, Karnes J, O'Brien PC, Zimmerman IR. Detection thresholds of cutaneous sensation in humans. In: P. J. Dyck, Thomas PK, Griffin J, Low PA, Poduslo JF, (eds). Peripheral neuropathy. 3rd ed. W. B. Saunders, Philadelphia, 1993: 706-28. 